\title{
A Case Report on Stab Injury
}

\author{
Asma Begum1, Md. Rabiul Huq², Meherunnessa Begum³, \\ Azmeri Alam4, Gulshanara Akhter5, Tamanna Tasmin6
}

\begin{abstract}
Stabbing is the most common method of homicide in developing countries like Bangladesh, due to poverty, over population, joblessness, political unrest, etc. The reported case is of a 27 years old man stabbed on the front of the left thigh, a relatively unusual site by a sharp pointed knife by some snatchers while sitting on a rickshaw. On medicolegal point of view the injury was homicidal in nature to run away without having a motive to kill the person. The site was easily approachable for the snatchers. We need to create awareness among general population about the circumstances and probable mishaps that can happen unexpectedly.
\end{abstract}

Keywords: Stab injury; homicide.

1. Assistant professor, Department of Forensic Medicine, Ibn Sina Medical College, Dhaka, Bangladesh.

2. Associate professor, Department of Forensic Medicine, Ibn Sina Medical College, Dhaka, Bangladesh.

3. Assistant professor, Department of Community Medicine, Ibn Sina Medical College, Dhaka, Bangladesh.

4. Assistant professor, Department of Biochemistry, Green Life Medical College, Dhaka, Bangladesh.

5. Associate professor, Department of Forensic Medicine, Ibrahim Medical College, Dhaka, Bangladesh.

6. Lecturer, Department of Forensic Medicine, Ibn Sina Medical College, Dhaka, Bangladesh.

Correspondence: Dr. Asma Begum. e-mail: mnpopy@yahoo.com

\section{Introduction}

Homicide means death of a person due to act of another. ${ }^{1}$ Stabbing is the most common method of homicide. Stab wounds are of major importance in forensic medicine as these are extremely common as homicide. In Britain stabbing with a knife is usually the most frequent mode of murder and manslaughter, primarily in domestic disputes and street violence. ${ }^{2}$

Whether it is suicidal, homicidal or accidental generally speaking, stab wounds are most commonly homicidal, next in occurrence suicidal and lastly accidental. Homicidal stab wounds are usually more than 1 in number, all are quite deep, may be located any where on the body, including self unapproachable parts. In homicidal cases covering clothes usually bear corresponding cut marks or tears. 1
By definition a stab wound is deeper than it is long and it is the depth of the injury that makes it so often fatal. ${ }^{3}$ A stab wound is produced when the force is delivered along the long axis of a narrow or pointed weapon, such as knife, dagger, nail, needle, spear, arrow, screw driver, etc, in the depth of the body that is deeper than its length and width on skin. ${ }^{4}$ Penetrating wound is applied to those puncture wound which, while passing through the tissues, enters a body cavity, like abdominal cavity, thoracic cavity, scrotal cavity, cavity of the knee joint or mouth cavity, etc. When a puncture wound enters the body surface on one side and comes out on the other side, a perforating wound is produced, like a sharp pointed weapon enters a ventral aspect of either forearm and comes out on the dorsal aspect. 5 It is also called through and through puncture wound. 
Puncture wound or stab wound can also be produced without causing penetration to a body cavity or without perforating the whole thickness of the body. Here the tip of the weapon terminates inside the body except in a body cavity. Bullet or pellet injuries are puncture wound caused by high velocity projectile. ${ }^{1}$

Puncture wound made by pins and needles especially on concealed parts of the body called concealed puncture wounds are commonly found in such parts of the body as anterior fontanellae, inner canthus of the eye, up the nostrils, down the throat, nape of the neck, axilla, vagina, rectum, etc. 6

\section{Case report}

A male of about 27 years old, was brought to the casualty department of Dhaka Medical College Hospital (DMCH) with an injury on the left thigh on 29/08/2007 around 7 PM. According to his statement on the way to home by a rickshaw, he was attacked by a group of snatchers. One of them within a short period of time put a sharp pointed knife on his left thigh and snatched his moneybag. At that time the victim protested and was stabbed on the front of the left thigh. The people from near by rushed to the spot and the assailants fled away. Then he was brought to the emergency department of DMCH.

On examination one punctured wound was found on left mid thigh anteriorly. The wound was measuring about 1"x0.5"x muscle depth. No major blood vessel was injured. The emergency medical officer stitched the wound after proper toileting, prescribed medicine and advised to come after one week for stitch off.

\section{Discussion}

Stabbing is one of the most frequent ways of committing homicide 7 , which may result from any sort of enmity, family dispute, quarrel with friends or even for snatching valuables. This is the picture not only in our country but worldwide. The most common sites of stabbing are chest and abdomen. 8 But this reported case presented with a relatively uncommon site of stab injury.

Precise examination of such injuries may reveal a sizeable number of clues which may be of paramount importance in reconstruction and interpretation of the whole events. In this case though medical evidence may not be enough to come to a conclusion, the statement of the victim gave it a shape in favor of homicidal attempt. According to the victim's statement, the injury was caused by sudden attack by some snatchers. There was no previous quarrel among the victim and the assailants. The weapon was sharp pointed, there was no intention to stab him, but on shouting the assailants were forced to stab him to prevent shouting. His statement and medico legal examination of the wound were in no contradiction as the depth of the wound was greater than the external length and breadth, which indicates that the wound was stab injury and the weapon was sharp pointed. Moreover it has to be remembered that direction is helpful to determine the relative position of the victim and assailant. ${ }^{6}$ In this case the direction of the wound was backwards downwards and medially. The victim was in sitting position in a rickshaw and the assailant was standing on the left side of the victim. The thigh was in horizontal position and the assailant used the weapon from above downwards and sufficient force was applied because the muscles were injured.

Snatching, robberies are not uncommon in our country. This is a common picture of Dhaka city and generally increasing day by day due to poverty, unemployment, frustration and drug abuse of our younger population. For better protection of ourselves we should be aware about the different patterns of attack and wounds encountered in such events. In this case the victim was attacked while sitting on a rickshaw which is one of the most common vehicles used by our common people in urban areas. And the unusual site of homicidal attempt seen in this case is the most easily approachable part of the body in such circumstances. Fatal outcome may occur in this type of injury. Though it would not hit any vital organ but large blood vessels might be severed and the victim might bleed to death.

\section{Acknowledgement}

The authors gratefully acknowledge the institutional ethical committee of $\mathrm{DMCH}$ to kindly provide the ethical approval for publication of the case. 


\section{References}

1. Nandy A. Mechanical Injuries. In: Principles of Forensic Medicine. 3rd ed. Kolkata: New Central Book Agency; 2010. p.330-81.

2. Knight B. The Pathology of Wounds. In: Saukko P, Knight B, editors. Knight's Forensic Pathology. 1st ed. Great Britain: Hodder Arnold; 1991. p.140.

3. Shepherd R. The Examination of the Wound. In: Simpson's Forensic Medicine. 12th ed. London: Arnold; 2003. p. 65 .

4. Reddy KSN. Mechanical Iinjuries. In: The Essentials of Forensic Medicine and Toxicology. 27th ed. Hyderabad: Mohan Printers; 2007. p.169.
5. Mallik CC. Injuries. In: A Short Text Book of Medical Jurisprudence. 3rd ed. Kolkata: The New Book Stall; 1993. p.421.

6. Parikh CK. Mechanical Injuries, General Aspects. In: Text Book of Medical Jurisprudence, Forensic Medicine and Toxicology for Class Room and Court Room. 6th ed. Bombay: CBS Publisher; 2007. p.418-21.

7. Singh VP, Sharma BR, Harish D, Vij K. A Critical Analysis of Stab Wound on the Chest - A Case Report. JIAFM. 2004;26(2):77-9.

8. Swann IJ, MacMillan R, Watson AA. A Study of Stab Wounds. Arch Emerg Med. 1985 March;2(1):31-6. 
